\title{
The Dark Side of Flow: A Qualitative Study of Dependence in Big Wave Surfing
}

\author{
Sarah Partington and Elizabeth Partington \\ Northumbria University \\ Steve Olivier \\ University of Abertay Dundee
}

\begin{abstract}
Flow has been described within sport psychology as an optimal state underpinning peak performance. However, the consequences of experiencing flow may not always be beneficial. One negative consequence might be that of contributing to dependence on the activity that interacts with, or is associated with, the flow experience. This study explored the dichotomous consequences of flow, using case studies of big wave surfers. Fifteen elite surfers completed in-depth, semistructured interviews. It seems clear from the results that the surfers experienced positive consequences of flow. However, they also exhibited symptoms of dependence on surfing. It is suggested that there may be an association between the experience of dimensions of flow and the compulsion to engage in an activity. Some specific recommendations for further research into the relationship between flow and exercise dependence are made.
\end{abstract}

When action and awareness merge, when goals seem clear and feedback unambiguous, when one is concentrated on the task at hand and feels both a sense of control and a loss of self-consciousness, then one is experiencing flow (Csikszentmihalyi, 1975, 1988, 1992). Flow is a state of optimal experience, a state "in which people are so involved in an activity that nothing else seems to matter; the experience itself is so enjoyable that people will do it even at great cost, for the sheer sake of doing it" (Csikszentmihalyi, 1991 p. 4).

Further, flow has been held to be a mental state evoked when one is poised between relaxation and anxiety. This balance depends upon the perceived matching of skills to challenges faced, both of which must be above a person's average. Flow has been depicted as the ultimate autotelic experience-one that is performed purely for its own ends (Csikszentmihalyi, 1975).

Part of the pleasure of flow comes from its dissociative nature, via the transcendence of the self that takes place (Stranger, 1999). When "the voice within has been silenced" (Celsi, Rose, \& Leigh, 1993, p. 17), the individual is free to act without the usual worries that plague our daily existence. Because there is no

S. Partington and E. Partington are with the School of Psychology and Sport Sciences, Northumbria University, Northumbria, England, UK. Olivier is with the School of Social and Health Sciences, University of Abertay Dundee, Dundee, Scotland, UK. 
awareness of the self during a flow state, physical and mental functioning appear to become one, with the result being that individuals experience not only satisfaction and catharsis, but they often also exceed their usual levels of performance (Jackson, 1992). As such, flow has been associated with peak levels of experience and peak levels of performance (Privette, 1981).

Flow research in sport psychology has moved beyond description. To establish how to create and sustain flow, the focus has been upon the psychosocial mechanisms or variables that may be causally related or associated with flow experiences. Variables include precompetitive plans, confidence, optimal arousal, motivational focus, and intrinsic motivation (Catley \& Duda, 1997, Jackson, 1995, Jackson, Kimiecik, Ford \& Marsh, 1998, Jackson, Thomas, Marsh \& Smethurst, 2001; Kimiecik \& Stein, 1992). The potential controllability of flow has also been looked at, with the majority of athletes questioned believing that flow is controllable (Cately \& Duda, 1997; Jackson, 1995). However, this unqualified acceptance of the positive consequences of flow fails to fully appreciate Csikszentmihalyi's contention about flow which holds that, while it is enjoyable, it may have negative costs associated with it (see earlier).

Csikszentmihalyi (2002) further suggested that flow can have addictive properties, explaining that "the self becomes captive of a certain kind of order, and is then unwilling to cope with the ambiguities of life" (p. 62). The individual may become driven to perpetually strive to recreate flow (Csikszentmihalyi, 2002). As such when studying flow, there is a need to consider that while flow may be associated with peak performance, it may also be associated with other less positive outcomes.

Within the context of sport and exercise, researchers have attempted to define dependence. Bamber, Cockrill, Rodgers and Carroll, (2003) proposed that evidence of impaired functioning is a diagnostic criteria for exercise dependence. According to Bamber et al. (2003) impaired functioning may be evidenced in four different areas: psychological; social/occupational; physical; and behavioral. The authors consider impairment in at least two of these four areas as necessary for diagnosis of dependence.

Similarly Hausenblaus and Downs (2002) claimed that evidence of three or more of the following seven features would qualify as a diagnosis of exercise dependence: tolerance (need to increase amount of exercise to achieve the desired effect); withdrawal (symptoms such as anxiety or fatigue when deprived of exercise); intention effects (exercise taken in greater amounts or for longer durations than was intended); loss of control (unsuccessful efforts made to reduce the amount of exercise taken); time (excess time spent on the exercise activity); conflict (occupational or social activities given up because of exercise); and continuance (continue to exercise despite impediments such as injury).

Despite such diagnostic criteria, dependence in sport and exercise remains under debate. Not only is there discussion as to whether the condition exists as a primary disorder (Bamber et al., 2003), but researchers have differing opinions as to whether exercise dependence (if it does exist) is positive or negative.

Exercise dependence could be positive because exercise participation can improve both psychological and physical strength (Glaser, 1976; Iannos \& Tiggeman, 1997). However, it could be argued that it is negative due to the experience of withdrawal symptoms when exercise is withheld and the belief by participants 
that they cannot cope without their daily fix (Morgan, 1979, as cited in Bamber et al., 2003; Robbins \& Joseph, 1980). Clearly, in a sport such as big wave surfing, dependence can have potentially negative effects as a result of the inherently dangerous nature of the activity. There have, for example, been several fatalities while engaging in the sport in recent years (Olivier, 2006).

In an effort to resolve such contradictions, Sachs (1982) suggested a continuum in which exercise for the negatively dependent individual has progressed from an important aspect of the individual's life to a controlling factor which dominates other choices. In contrast, the positively dependent individual retains control. Similarly, Pargman (1980) distinguished between runners who were addicted/dependent and those who were committed/dedicated, with the distinction being made primarily on the basis of whether the involvement in running was on a rational and pragmatic basis, or for the emotional or euphoric feelings associated with the activity.

Given this lack of consensus regarding dependence, it is not surprising that the potential addictive qualities of flow have not been considered in sport. However, we feel that flow should be studied from a broader perspective, one that allows potential negative consequences to be considered as well. After all, while Csikszentmihalyi (2002) acknowledged that flow may increase the richness of life, he also warned that we must look at the larger, potentially negative consequences of any individual instance of flow. Such an investigation has yet to be conducted in sport.

Csikszentmihalyi (2002) strongly suggested that we "need to learn to distinguish the useful and the harmful forms of flow, and then make the most of the former while placing limits on the latter" (p. 70). This is not to say that flow itself is either good or bad, rather that such a state may be associated with both positive and negative consequences. It is beyond the scope of this paper to isolate flow as the causal factor in exercise dependence. Indeed it would be inappropriate to attempt to make such a claim given the complexity of human motivation and the multitude of factors likely to underpin it, and we acknowledge that flow is dependent on the balance of perceived challenge and the athlete's skills ${ }^{1}$. A similar comment could be made about trying to claim flow as the one causal factor underpinning peak performance, but we are not attempting to establish a cause-effect relationship. The aim of this paper is to redress the balance in the study of flow and to take a broader perspective than has so far been taken in sport psychology, and we do so by exploring potential negative connotations.

To explore flow experiences and their potential negative consequences, it is necessary to find an activity in which flow frequently occurs. Risk is one factor that has been described as an effective catalyst for reaching transcendent states such as flow (Stranger, 1999). Csikszentmihalyi (1990) explained the link between flow and risk as the combination of high challenges and high skills. While there must be a skill-challenge balance Csikszentmihalyi stated that both the skills and challenges must be above a person's average.

Accounts of the nature of thrill in risk-taking leisure activities often emphasize the ecstatic feelings of oneness with the environment, the loss of self in the activity, and an intense awareness of the moment (Stranger, 1999). In fact states such as this have been found to be key motivating factors for participation in risk sports (Celsi, et al. 1993, Stranger, 1999). 
Given the findings described above, it is plausible to suggest that participants in risk sports are likely to experience flow. "Big wave" surfing is an activity that carries the possibility of serious injury and even death. As such, it is a sport that includes challenge and risk and requires great skill. Big wave surfing was thus deemed a suitable context for exploring flow. The current study therefore focused upon a group of elite big wave surfers to examine both the positive and negative consequences of experiencing flow.

\section{Methods}

\section{Participants}

The sample was comprised of 15 of the world's top big wave surfers (12 men and 3 women, mean age 37.0 years). Countries of origin of the surfers included Hawaii (note that Hawaii is referred to as a country in competitive surfing, as distinct from the USA); Australia; and South Africa. The gender bias was dictated by the nature of the activity, in that there are fewer women than men who surf big waves. The population seems relatively old in comparison with other elite sport studies, but successful big wave surfing has historically demanded a long apprenticeship, hence the seemingly advanced age of participants. The mean age was also skewed by two older surfers who are no longer as active, but who are recognized to be pioneers of the sport.

Those who participate in such contests are acknowledged both by their peers and by the media as big wave surfers. Participation in these contests is by invitation only. Such invitations are issued on the basis of past achievement and/or peer recognition. Potential participants for a study of this nature were thus identified as being part of a selected pool of elite contest competitors.

All participants in the study were extremely high achievers in this elite category of surfing, and were selected for participation on this basis. For example, participants included past winners of the Eddie (probably the most prestigious big wave contest), Mavericks, the Red Bull contest, two winners of the Billabong XXL Big Wave Challenge, as well as two former World Champions.

Big wave surfers are a small elite subset of the larger surfing subculture. They are recognized as big wave surfers at least in part by their participation in specific surf contests. What constitutes a big wave contest is defined by the size of the surf. The size limit deemed to be acceptable for a contest to run is a subjective judgment made by an experienced contest director, but it is accepted in the surfing world that the handful of recognized big wave contests are held in conditions that others would consider extreme and dangerous. Given their experience and elite status, it was felt that these surfers would provide appropriate information-rich cases (Sparkes \& Partington, 2003) for the study.

\section{Procedure}

The study was approved by the University's Ethics Committee. Initial access to participants was via the third author's long-standing relationship with a key figure in surfing administration, who acted as a gatekeeper to the culture (Hammersley \& Atkinson, 1995). A participant pool was discussed with the gatekeeper, and 
individuals were selected according to the criteria identified above (i.e., invited participation in elite big wave events). Potential participants were contacted by the gatekeeper and asked if they would consent for their contact details to be passed on to the third author, to discuss the possibility of participating in a study on big wave surfing. Those who agreed were subsequently contacted by telephone by the third author, who orally explained the project to them. Three surfers of the original eighteen contacted were unable to participate due to other commitments.

Following this oral explanation, the third author met with each participant and informed consent forms were administered and completed. Participants were then offered the opportunity to ask further questions before the completion of oneto-one semi structured interviews. Interviews lasted one to two hours and took place in Hawaii and South Africa at times that coincided with a high concentration of the world's best performers being present at the same locations. The majority of the interviews took place in private locations such as the third author's hotel room or the participant's home or office, where conditions were conducive to indepth conversation. In two cases, semiprivate locations were necessary to ensure participation. For example, two interviews took place in a quiet corner of the judging area during a surfing competition. While it is acknowledged that this was not ideal and may have resulted in less effusive discussion, the schedules of these two participants meant that access to them was only possible at these times.

To strike a balance between structure and flexibility, a semistructured interview guide was created. The guide was a collection of related topics, as opposed to the detailed set of questions and probes that characterize a structured interview schedule (Patton, 1990). In generating the guide, the principles suggested by Maykut and Morehouse (1994) were followed, beginning with brainstorming topics and ideas related to the focus of inquiry and eventually categorising and sequencing them.

The recommendation of Patton (1990) to provide a framework within which the respondents can express their own understanding in their own terms (p. 290) was followed. As such the interview guide was comprised of a series of categories that provided a range of issues to talk around. Categories included participation motivation in risk sports, as well as flow and dependence (e.g., Celsi et al., 1993; Csikszentmihalyi, 1975; Jackson, 1992; Stranger, 1999), with a focus on perceptions of risk/danger, experiences of flow, motives for both initial and continued participation and the transition from surfing small waves to big waves. As this study was part of a wider study, which also explored moral justification for risktaking (see Olivier, 2006), not all the questions asked were of direct relevance to flow (for example some questions focused on childhood experiences and socialisation into sport). With regard to the flow section of the project, participants were told that they would be asked to talk about their reasons for engaging in big wave surfing, with a focus on perceived risks, benefits, challenges and consequences of participation. Within this, participants were told that the researcher was particularly interested in optimal experiences and the relationship between such experiences and participation motivation. Specific questions related to mastery, confidence, fear, progression to bigger surf, skills and abilities needed, hierarchy, control, concentration, escapism, freedom, near death experiences, achievements, 
and reasons for participation. Basic, explanatory, focused, silent, suggestive, and mirror probes were prepared as interview facilitation tools.

According to Atkinson (1998) an interviewer must know how to invite stories as responses. Following the advice of Chase (1995) the aim was to encourage the participants to take responsibility for the meaning of their talk. Thus, rather than engaging them in abstract discussion, they were asked to talk about their own personal experiences. The first question (How did you get involved in surfing?) opened up the floor to the interviewee and the interview progressed from there.

\section{Data Analysis and Results}

Following transcription of the interviews, the first author read the transcripts several times, making notes and seeking to gain an understanding of the interviewee's point of view (Maykut \& Morehouse, 1994). Next a constant comparison method of data analysis (Glaser \& Strauss, 1967) was employed. During this process, the data were analyzed for emerging categories and themes, which were then organized into successively broader and more abstract categories. The initial level of analysis involved using the surfers' direct quotes to create raw themes. Sections of text were extracted and classified in order that they could be gathered into similar and disparate categories (Coffey \& Atkinson, 1996; Maykut \& Moorehouse, 1994).

Once initial categories were established, connections were made to theoretical constructs that seemed to be related to the specific issues emerging from the participants' stories. Analogous and relevant quotes by all surfers were identified and considered for use as illustrative examples, and the results of these can be seen in Figures 1 through 3. However, those used in full as examples, while representative, were confined to eight of the group. The justification for this usage is that these statements were made by those that might reasonably be deemed the more erudite individuals, and those statements thus contributed more toward capturing the essence of a particular theme. To ensure that these were in fact representative, peer debriefing was employed (see later).

When the initial list of raw themes was complete, an inductive analysis was performed to generate a set of higher order themes (Jackson, 1995). This process involved examining raw themes and comparing them with all other themes at a particular level, integrating themes with similar meaning while separating themes with different meaning. Finally themes were integrated into more general, abstract dimensions.

As part of this analysis, methods of establishing data trustworthiness were deemed appropriate (Jackson, 1995). It has been noted that use of certain techniques provides greater credibility (Patton, 1990); however the notion of validity has proved problematic in direct application to qualitative work (Sparkes, 1998). Techniques used in this study included detailed description of the data collection and analysis process, and the employment of a system of peer debriefing within the research team. Here the first author was required to make a defendable case to the second and third authors, that her categorization of themes was supported by the data (Sparkes \& Partington, 2003). 
The role of peer debriefing was not to create intersubjective reliability, but rather to create a theoretical sounding board to encourage reflection upon and exploration of alternative interpretations (See Faulkner \& Sparkes, 1999; Sparkes $\&$ Partington, 2003). The aim was not that all researchers agree on the criteria, but rather that a defendable and plausible interpretation could be accepted while still acknowledging that other plausible interpretations might also exist. As such the process served to develop notions of authenticity and believability rather than validity (Sparkes, 1998).

\section{Experience of flow}

As shown in Figure 1, it was clear that most of the surfers experienced elements of flow. C's comment captures the overall flow experience:

I know that in some sports they talk about the zone, the place where your mind goes, and when you surf the best, you are in the zone. You are there alone. It is you, the wind, the waves, the salt in your mouth and the vision of the bumps and the chop and the sucking phase. There is nothing else there. There is nothing else in your mind. There is nothing else that matters. For a moment in time, time stands still and you are able to control the most uncontrollable because everything becomes slow motion and that's when you know you are surfing the best. Everything is like . . . it is your time to go and you look around and you can see the variations in the face and you can see the chops and everything is like coming to you real slow. (Participant C).

\section{Dependence}

In Figure 2, D's use of the term 'addiction' when discussing his need to surf was shared by many of the surfers:

There is a risk of dying, of breaking bones, but the feeling you get off it (flow) is like no other feeling in the world. The best drugs cannot get you the same level of ecstasy, feeling of really good adrenaline. Once you get familiar with that feeling it's an addiction. (Participant D).

Some of the surfers experienced tolerance and discussed the need to go further, higher or faster to continue to experience the desired feelings. Participant $\mathrm{C}$ spoke of the "desire to go further than you have gone before", explaining that "nothing is ever enough"; while others discussed the specific need to increase the challenge to continue to achieve the experience. Participant A spoke about how his involvement escalates as he attempts to heighten his flow: "It's an exhilaration of adrenaline which kinda causes wanting more and more you know? After each turn, you want to accelerate faster in to the next turn. It's a self-perpetuating feeling of kinda aggressive euphoria" (Participant A).

When talking about why they surfed, several of the surfers prioritized the euphoric feelings they experienced during flow moments over more material and arguably more rational incentives such as monetary reward: 


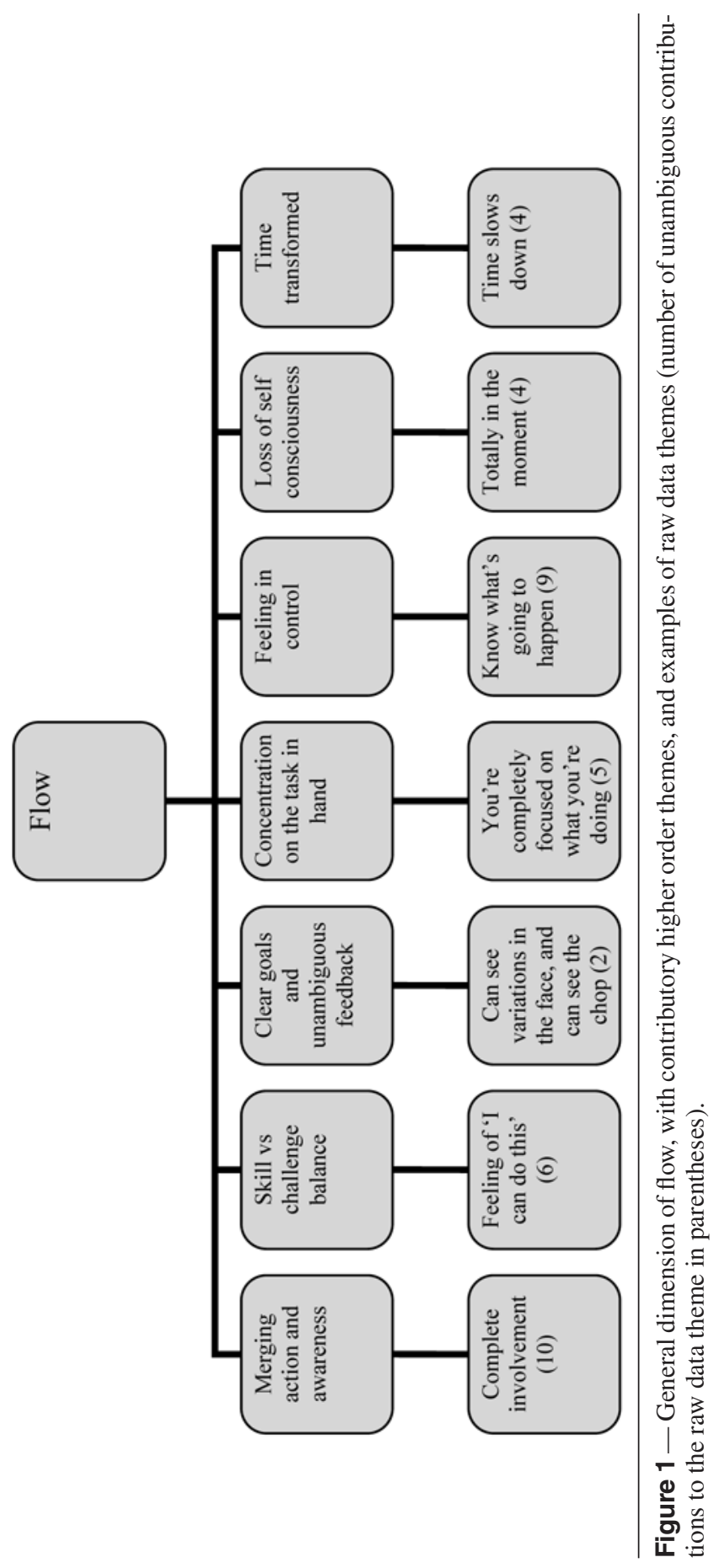




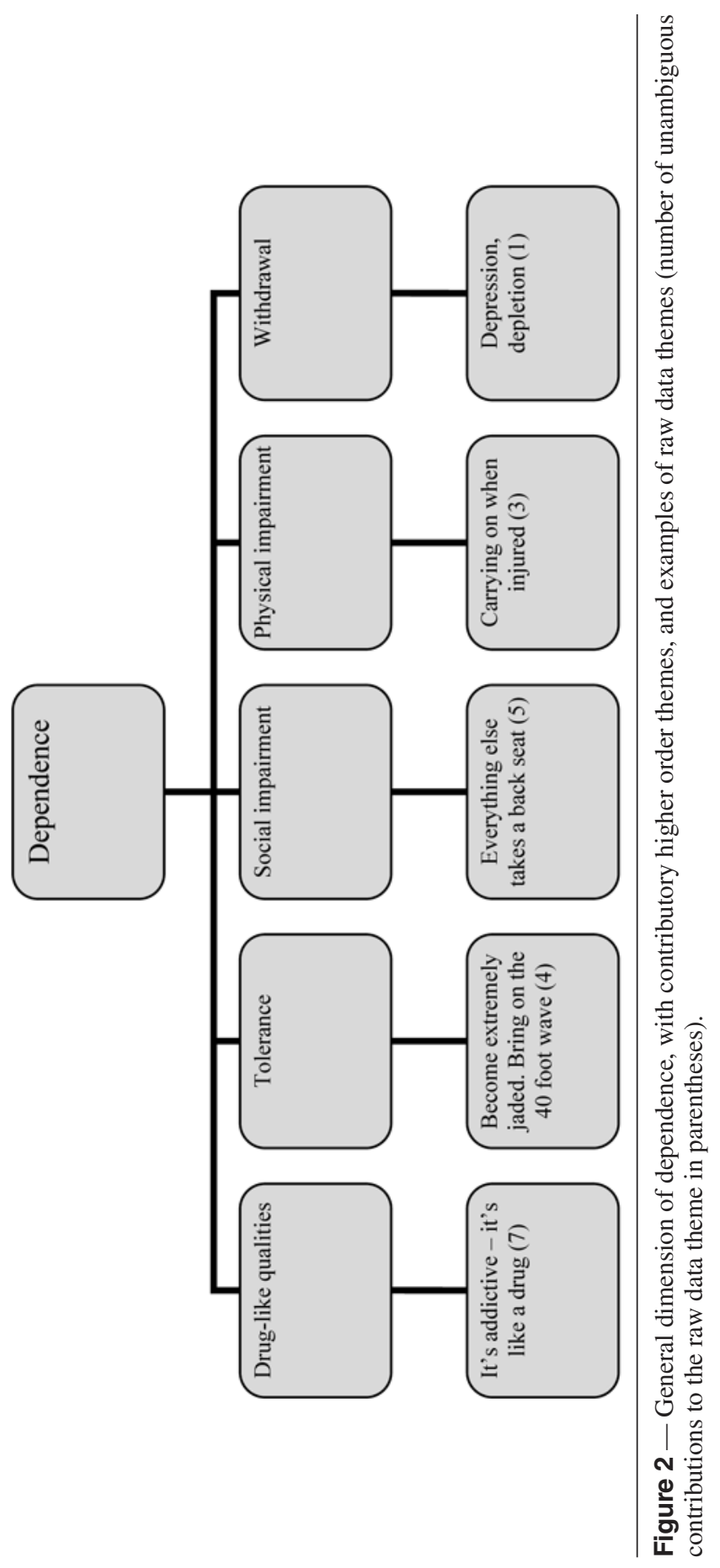


I don't get paid for this. I still don't get paid for this and I never have been paid for it, yet I can't wait for each next swell. (Participant C).

Some surfers, such as Participant B, exhibited behavior that could be classified as an example of 'social impairment':

My husband like wants to have babies. I kinda don't cause I want to keep surfing you know? Gosh it's kinda like once you are in it, you are almost stuck in it almost, you know? It's like you are in the club and in order to keep doing it, you have to keep doing it all the time. (Participant B).

Perhaps the most extreme example of social impairment can be seen in the comments of Participant A, who stated clearly that for him the pleasure of the flow experience gained while surfing outweighed everything else, even his life:

I mean the pleasure for me; the pleasure outweighs the risk you know. And maybe that's not saying much for my regard for, for my life, for my health, but, but I guess I am willing to take the chance of you know, of any pain or suffering it might cause over the benefits of the rush. (Participant A).

Other surfers such as Participant $\mathrm{H}$ talked about continuing to surf despite injury. This could be viewed as physical impairment:

I have heard that a separated rib is more annoying than a broken rib . . . It went on for over six months. I tried to pad it, put on wetsuits. I couldn't stop surfing, so it prolonged the injury and healing times. (Participant $\mathrm{H}$ ).

Participant $\mathrm{H}$, in another quote, discussed in detail his desire to experience the positive feelings associated with flow when surfing, and the withdrawal symptoms he suffered when he was not able to experience it:

You just get a taste of it and I think it becomes addictive almost. It's something you can't quench, you can't satisfy and you chase it . . It's there for a period of time and then you kinda hang your guns up for a while, dry out and then think when can I do it again? There is psychologically after all that is done, there is a depression almost. You are sort of depleted and the only way to satisfy it is to do it again. The addiction is kinda funny. (Participant $\mathrm{H}$ ).

Finally, many of the surfers used drug analogies when talking about their desire to recreate the feelings experienced when surfing:

It's like a drug or something. I've tried all the drugs back in the day. (Participant G).

We actually get high off it. (Participant $\mathrm{H})$.

\section{Fulfillment}

In Figure 3, analysis of the results indicated that the surfers gained the psychological benefits from experiencing flow that have been described in previous 


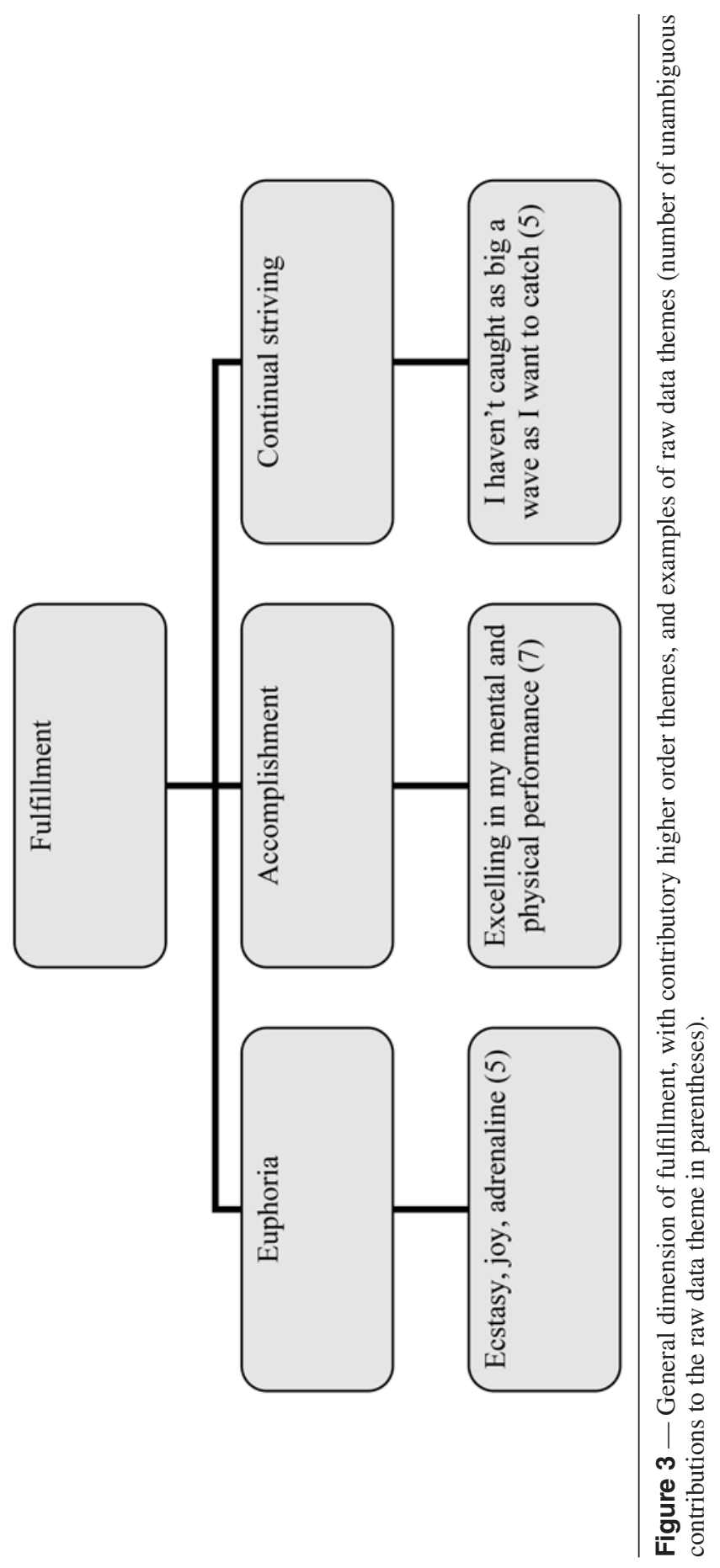


research. For example $\mathrm{K}$ and others reported both the euphoria and the enhanced performance that have generally been associated with flow:

I think it's probably the most exciting and wonderful feeling that you can have, cause you are looking at a beautiful wave and you know that you are on a big wave and you are riding it well and that's an accomplishment that will live with you the rest of your life. (Participant K).

Some of the surfers felt that in chasing the experience of flow, and as a consequence experiencing both euphoria and enhanced performance, they were chasing a sense of achievement and ultimately reaching some sort of fulfillment.

I kinda feel like I do better under pressure, even in work situations and everything else around me. So putting that on me throwing me into a big wave enables me to excel. I feel that I am excelling in life, in my performance, my physical and mental performance. (Participant A).

However, many of the surfers commented that they were continually striving to achieve more. They want to see how far they can go, how big a wave they can ride and are not yet satisfied with their performance:

I've figured out how to be out there and not get killed but I haven't figured out how to get on a very huge one and that's what keeps me going out. I would really like to get that big one. (Participant B).

Participant $\mathrm{N}$ viewed this continual striving very negatively, explaining that through surfing he is chasing a sense of fulfillment via flow that he will never truly attain:

I am quite nervous about my motive for big wave riding and if I had to be blatantly honest, I think there is some kind of ego trip, which is a desire to find an identity and fulfill a lack inside of, lets call it affirmation. You ride a 25 foot wave and people interview you on television, it's part of an affirmation in a sense that you are right, that you are doing pretty well. I think all of us as human beings have this need for affirmation and we try and find it in all sorts of ways. It comes back to that ego and that searching for a fulfilment. I don't think big wave surfing will fulfill. I think people will be just as empty when they have found the 100 foot wave. Nothing fulfils me, so I have tried other things and then you start trying the dangerous things and the drug things. I think people will be just as empty when they have found the 100 foot wave. They will say 'what now? We are still as lonely as we were before. (Participant N).

Taking this further, Participant N suggested that underlying psychological dysfunction might play a role in compelling big wave surfers to chase fulfillment through the experience of flow. In other words, due to personal inadequacies, some people are more vulnerable to the potential negative consequences of flow:

The big wave riders fall in to a group called the extremists. If you look at that, I mean I have been an extremist drug taker in my past. I nearly blew it big 
time in life. It was just another area of extremism. . . If they are truthful with you, you will probably find that a large percentage grew up in unstable home environments. My only influence in big wave surfing was my dad, but my instability was my dad. My dad was a serious drinker and there was a lot of arguing and fighting within the home... . It was unstable for myself growing up in that environment. The same reason that I did drugs is the same reason that I do big wave riding, and that's sad. . . . If you were a confident, emotionally stable person, you are confident as to why you are on this planet there is no reason to go over the speed limits that you work. (Participant N).

\section{Discussion}

Although we cannot claim a direct measure, it seems clear from their comments that many of these surfers experienced flow as defined by Csikszentmihalyi (1975). Surfers talked about times when they felt a match between skills and the challenge they had encountered, when there was a merging of self and awareness, and they exhibited high levels of concentration, felt in control of their performance, and noticed alterations in their perceptions of time. While the surfers enjoyed feelings of flow and reported both momentary and long-term benefits in relation to both mood and performance (Jackson, 1992; Privette, 1981; Williams \& Krane, 1993), they also talked about feeling addicted to the optimal sensations and experiences that they had while surfing.

Pargman (1980) distinguished dependence from commitment on the basis that dependent individuals are participating primarily to experience euphoric feelings, rather than participating for more rational purposes. This seemed to be evident in the comments of some of these surfers who identified the sensations as the primary motivator rather than for example financial incentives.

In the same way that habitual drug addicts may need to continually increase their dosages to gain the appropriate sensations, some of these surfers found that they needed to increase the speed and size of the wave that they were surfing to recapture the feelings that they had previously experienced. Such accounts are reminiscent of Hausenblaus and Downes' (2002) notion of tolerance, a construct they view as central to a definition of dependence.

Morgan (1979) and Sachs (1982) specified that an individual was only negatively dependent on an activity if he or she had lost control of his/her participation in that activity and allowed the activity to dominate all other choices. In the case of some of the surfers surfing was placed before other activities such as starting a family, gaining employment, and attending social events. Several surfers could be classified as exhibiting this 'social impairment' on Bamber et al.'s (2003) dependence scale, or 'conflict' if the terminology of Hausenblaus and Downes' (2002) is used. Similarly, continuing to participate when injured would be classified as physical impairment on Bamber et al.'s (2003) dependence scale, and linking back to Sachs (1982), would also indicate a loss of control.

We acknowledge the possibility that the activity itself may be responsible for dependence, rather than flow per se. Nevertheless, while we are not claiming in this paper to have found a causal relationship between flow and dependence, we do suggest that for some of these surfers, elements of the flow experience such as 
the skill challenge balance may be associated with the desire to surf. Such suggestions are in accordance with the work of Iannos and Tiggeman (1997) who argued that high levels of physical activity can contribute positively to a sense of selfesteem, and fits with the general notion of the positive consequences of flow (Jackson, 1992; Privette, 1981).

Several surfers in this study spoke of the feeling of accomplishment and the rush that they experienced when their skills were found to match the significant challenge that they had taken on. The notion of continually striving to increase both the challenge and the skill and as result increase the associated feelings was a common theme in this study.

However, there was also a less positive view of the pursuit, which was expressed as the futility of constant striving, and the improbability that satisfaction would ever be attained. People will always want to go higher or faster to increase the challenge just a little more. The view held suggested that the fruitless pursuit could be viewed as a sign of personality dysfunction. These comments are in direct contrast to the findings of Iannos and Tiggeman (1997), who examined the personality characteristics of high level exercisers and found no evidence of personality dysfunction. However, it could be argued that these differences were due to the fact that Iannos and Tiggeman (1997) did not include risk sport participants in their sample. It was also suggested that risk sports participants may be particularly vulnerable to this negative behavior due to their dysfunctional personalities. Although this comment was not commonly expressed, it is not an unreasonable suggestion. Because Csikszentmihalyi (1975) has indicated that some people may be more susceptible to the experience of flow based upon their 'autotelic' personalities, it is possible that people may also be more susceptible to any negative consequences of experiencing flow based on their individual personality characteristics.

\section{Conclusion}

Heeding Csikszentmihalyi's (2002) call for a more rounded view of flow, we investigated the flow experiences of big wave surfers, being open to the possibility of finding both positive and negative consequences of experiencing flow. We contend that it is likely that these surfers did in fact experience flow while surfing, and that flow was likely to be associated with improved mood states, performance, self-esteem and fulfillment.

However, application of both Bamber et al.'s (2003) and Hausenblaus and Downs' (2002) diagnostic criteria for exercise dependence indicated that some of the surfers exhibited characteristics of dependence on surfing. Surfers talked of being addicted to the euphoric feelings experienced, and were willing to continue to surf despite family commitments, injury or potential death, to replicate these sensations.

Because some of the surfers were controlled by their surfing experiences, rather than in control of them, they could be classified as having a negative dependence on surfing (Sachs, 1982). Several of the surfers themselves confessed to being unable to function 'normally' in society because of their involvement in surfing, and there was the suggestion that the personalities of big wave surfers make them particularly susceptible to dependence. 
While this article does not claim to have found a causal relationship between flow and dependence, it is reasonable to suggest that there is an association. Indeed Csikszentmihalyi himself actually suggested that flow may have addictive qualities. In particular, several of the surfers talked of the rush that they felt when their skills were found to match a particularly difficult challenge (one that is above average) and the desire to replicate this feeling. This experience of the skill challenge balance has been identified as a key dimension of flow (Csikszentmihalyi, 1975), and it is possible that the desire to experience this aspect of flow, and possibly others, may be associated with a compulsion to continue with an activity. The findings of the current study concur with Csikszentmihalyi's (2002) more rounded view of flow, and its potential addictive qualities, in suggesting that the experience of flow within big wave surfing should not be viewed as a wholly positive phenomenon. Having raised awareness of the need to consider the dichotomous consequences of flow, it is suggested that future research should focus upon the potential interaction between the different dimensions of flow and dependence in other sport and exercise settings. Within extreme sports, the potential role of flow or dimensions of flow as precipitators of a willingness to engage in increasingly risky activity needs to be explored more fully. Finally, susceptibility to dependence due to flow or dimensions of flow needs to be studied in more detail. There is a need for a focus on sports and leisure contexts, and personality variables that may predispose individuals to be more susceptible to the potential negative consequences of flow, such as dependence.

\section{Author Note and Acknowledgment}

We acknowledge the input of an anonymous reviewer on this issue.

\section{References}

Atkinson, R. (1998). The Life Story Interview. Qualitative Research Methods Series 44. London: Sage publications.

Bamber, D.J., Cockrill, I.M., Rodgers, S., \& Carroll, D. (2003). Diagnostic criteria for exercise dependence in women. British Journal of Sports Medicine, 37, 393-400.

Catley, D., \& Duda, J.L. (1997). Psychological antecedents of the frequency and intensity of flow in golfers. International Journal of Sport Psychology, 28(4), 309-323.

Celsi, R.L., Rose, R.L., \& Leigh, T.W. (1993). An exploration of high-risk leisure consumption through skydiving. The Journal of Consumer Research, 20(1), 1-23.

Chase, S. (1995). Taking narrative seriously: Consequences for method and theory in interview studies. In R. Josselson \& A. Lieblich (Eds.), Interpreting experience: The narrative study of lives (pp. 1-126). London: Sage.

Coffey, A., \& Atkinson, P. (1996). Making sense of qualitative data. London: Sage.

Csikszentmihalyi, M. (1975). Beyond boredom and anxiety. San Francisco: Jossey-Bass.

Csikszentmihalyi, M. (1988). The flow experience and its significance for Human Psychology. In M. Csikszentmihalyi \& I.S. Csikszentmihalyi (Eds.), Optimal experience: Psychological studies of flow in consciousness (pp. 364-383). New York: Cambridge University Press.

Csiksentmihalyi, M. (1990). Flow: The psychology of optimal experience. New York: Harper and Row.

Csikszentmihalyi, M. (1991). Flow the psychology of optimal experience: Steps towards enhancing the quality of life. New York: HarperCollins. 
Csikszentmihalyi, M. (1992). Flow: The psychology of happiness. London: Rider.

Csikszentmihalyi, M. (2002). Flow: The classic work on how to achieve happiness. London: Rider.

Faulkner, G., \& Sparkes, A. (1999). Exercise as therapy for schizophrenia: An ethnographic study. Journal of Sport \& Exercise Psychology, 21, 52-69.

Glaser, W. (1976). Positive addiction. New York: Harper and Row.

Glaser, B.G., \& Strauss, A.L. (1967). The discovery of grounded theory strategies for qualitative research. Chicago: Aldine.

Hammersley, M., \& Atkinson, P. (1995). Ethnography. London: Routledge.

Hausenblaus, H.A., \& Downs, D.S. (2002). Exercise dependence: A systematic review. Psychology of Sport and Exercise, 3, 89-123.

Iannos, M., \& Tiggeman, M. (1997). Personality of the excessive exercisers. Personality and Individual Differences, 22, 775-778.

Jackson, S.A. (1992). Athletes in flow: A qualitative investigation of flow states in elite figure skaters. Journal of Applied Sport Psychology, 4(2), 161-180.

Jackson, S.A. (1995). Factors influencing the occurrence of flow in elite athletes. Journal of Applied Sport Psychology, 7(2), 135-163.

Jackson, S.A., Kimiecik, J.C., Ford, S., \& Marsh, H.W. (1998). Psychological correlates of flow in sport. Journal of Sport \& Exercise Psychology, 20, 358-378.

Jackson, S.A., Thomas, P.R., Marsh, H.W., \& Smethurst, C.J. (2001). Relationship between flow, self-concept, psychological skill, and performance. Journal of Applied Sport Psychology, 13, 129-153.

Kimiecik, J.C., \& Stein, G.L. (1992). Examining flow experiences in sport contexts: conceptual issues and methodological concerns. Journal of Applied Sport Psychology, 4, $144-160$.

Maykut, P., \& Morehouse, R. (1994). Beginning qualitative research. London: The Falmer Press.

McInman, A., \& Grove, R. (1991). Peak moments in sport: A literature review. Quest, 43, $333-351$.

Morgan, W.P. (1979). Negative addiction in runners. The Physician and Sportsmedicine, 7, 57-70.

Murphy, M. (1977). Sport as yoga. Journal of Humanistic Psychology, 17, 21-33.

Olivier, S.C. (2006). Moral dilemmas of participation in dangerous leisure activities. Leisure Studies, 25(1), 95-109.

Pargman, D. (1980). The way of the runner. In R.M. Suinn (Ed.), Psychology in Sports: Methods and Applications (pp. 90-98). Edina, MN: Burgess International.

Patton, M.Q. (1990). Qualitative evaluation and research methods (2nd ed.). Newbury Park: SAGE Publications.

Privette, G. (1981). Dynamics of peak performance. Journal of Humanistic Psychology, 21(1), 57-67.

Robbins, J.M., \& Joseph, P. (1980). Commitment to running: implications for the family and work. Sociological Symposium, 30, 87-107.

Sachs, M.L. (1982). Compliance and addiction to exercise. In R.C. Canty (Ed.), The exercising adult (pp. 19-27). Boston: Collamore Press.

Sparkes, A. (1998). Athletic identity: An Achillies' heel to the survival of self. Qualitative Health Research, 8, 644-664.

Sparkes, A.C., \& Partington, S. (2003). Narrative practice and its potential contribution to sport psychology: The example of flow. The Sport Psychologist, 17(3), 292-317.

Stranger, M. (1999). The aesthtics of risk: A study of surfing. International Review for the Sociology of Sport, 34(3), 265-276.

Williams, J.M., \& Krane, V. (1993). Psychological characteristics of peak performance. In J.M. Williams (Ed.), Applied Sport Psychology: Personal growth to peak performance (pp. 137-147). Mountain View, California: Mayfield. 
Copyright of Sport Psychologist is the property of Human Kinetics Publishers, Inc. and its content may not be copied or emailed to multiple sites or posted to a listserv without the copyright holder's express written permission. However, users may print, download, or email articles for individual use. 